\title{
Investigation of SiC Single Crystal Polishing by Combination of Anodic Oxidation and Mechanical Polishing
}

\author{
Xincheng Yin ${ }^{*}$, Shujuan Li $^{*}$, Peng Chai \\ School of Mechanical and Precision Instrument Engineering, Xi'an University of Technology, Xi'an \\ 710048, Shaanxi, China. \\ *E-mail: albertyinxc@163.com (X. Yin), shujuanli@xaut.edu.cn (S. Li)
}

doi: $10.20964 / 2020.05 .66$

Received: 3 Janary 2020 / Accepted: 27 February 2020 / Published: 10 April 2020

\begin{abstract}
For high-quality and effective polishing of $\mathrm{SiC}$, a novel polishing technique that combines anodic oxidation and mechanical polishing (AOMP) is proposed herein. To clarify the SiC surface anodic oxidation mechanism, AOMP experiments were conducted. The results show that as a result of surface oxidation, the main elements of the modified surface were $\mathrm{Si}$ and $\mathrm{O}$ by X-ray diffraction (XRD), indicating that the $\mathrm{SiC}$ surface was modified and formed a $\mathrm{SiO}_{2}$ oxide layer. Micro Vickers hardness tests revealed that the hardness of the modified surface greatly decreased to $1 / 9$ of that of the as-received surface, which was easy to remove. Considering the experimental results, an anodic oxidation process model is proposed herein based on the inner-outer double-directional diffusion theory. During the oxidation process, a transition layer containing silicon oxycarbide ( $\mathrm{Si}-\mathrm{C}-\mathrm{O})$ was formed between the $\mathrm{SiO}_{2}$ and $\mathrm{SiC}$, the amount of which varied with the thickness of the oxide. Based on the Deal-Grove model, the relationship between the oxide layer thickness and oxidation time was determined, and the initial oxidation rate was $44.81 \mathrm{~nm} / \mathrm{min}$. The surface roughness after chemical mechanical polishing (CMP) was determined for different oxidation time and polishing time, and it was clear that when the anodic plasma oxidation rate matched the CMP rate, a just-polished surface was obtained.
\end{abstract}

Keywords: SiC single crystal; anodic oxidation; mechanical polishing; mechanism

\section{$\underline{\text { FULL TEXT }}$}

(C) 2020 The Authors. Published by ESG (www.electrochemsci.org). This article is an open access article distributed under the terms and conditions of the Creative Commons Attribution license (http://creativecommons.org/licenses/by/4.0/). 